\title{
CNS and cutaneous involvement in tuberous sclerosis complex
}

\section{Comprometimento cutâneo e do SNC no complexo esclerose tuberosa}

Fernanda Frotte Bopp Salomon'1, Miriam Menna Barreto', Gláucia Zanetti', Rosana Souza Rodrigues ${ }^{1,2}$, Emerson Leandro Gasparetto', Edson Marchiori ${ }^{1}$

A 13-year-old boy with tuberous sclerosis complex (TSC) presented with a painless, gradually progressive area of thickened skin in the occipito-cervical region corresponding to a giant shagreen patch (Figure A). Physical examination demonstrates facial angiofibromas (Figure B) and periungual fibromas. He also presented mental retardation and tonic-clonic seizures. MRI revealed a subependymal nodule in the lateral ventricle, cortical tubers and the shagreen patch (Figures $\mathrm{C}$ and D).

The diagnosis of TSC is based on clinical criteria ${ }^{1,2}$. In our patient brain MRI was able to demonstrate at least three TSC major features, which met the criteria for a definitive diagnosis.
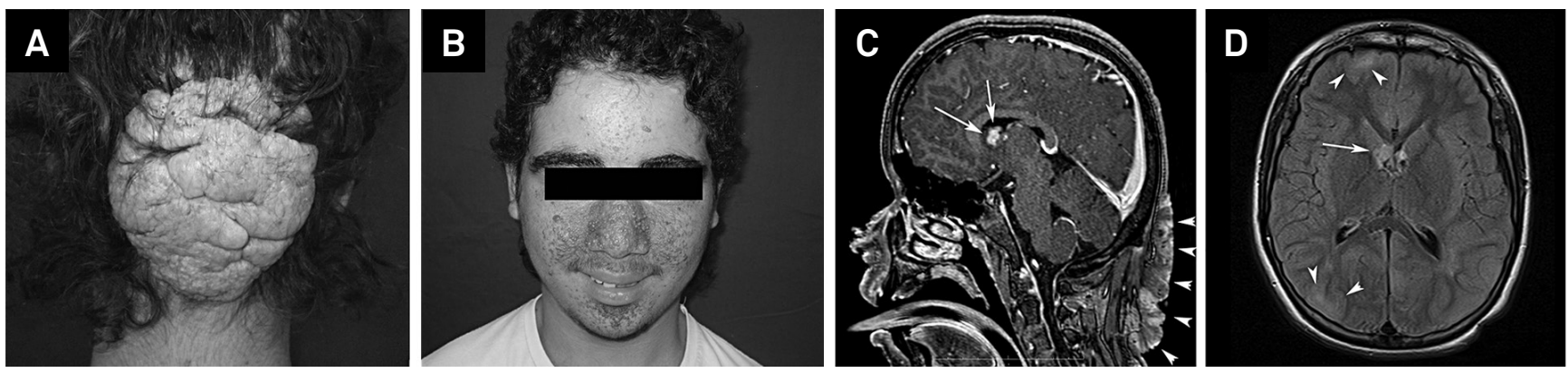

Figure. (A) A large shagreen patch located in the occipito-cervical region. (B) Multiple facial angiofibromas over the centrofacial areas. (C) Sagital T1-weighted and (D) Flair MRI shows subependymal nodules in the lateral ventricle close to the Monro foramina, suggesting giant cell subependymal astrocytoma at the right (arrows) and cortical tubers (arrowheads). Note also in C the shagreen patch (arrowheads).

\section{References}

1. Crino PB, Nathanson KL, Henske EP. The tuberous sclerosis complex. N Engl J Med. 2006;355(13):1345-56. doi:10.1056/NEJMra055323
2. Curatolo P, Bombardieri R, Jozwiak S. Tuberous sclerosis. Lancet. 2008;372(9639):657-68. doi:10.1016/S0140-6736(08)61279-9

\footnotetext{
UUniversidade Federal do Rio de Janeiro, Departamento de Radiologia, Rio de Janeiro RJ, Brazil; 2D’Or Instituto de Pesquisa e Educação, Departamento de Radiologia, Rio de Janeiro RJ, Brazil. Correspondence: Edson Marchiori; Rua Thomaz Cameron, 438; 25685-120 Petrópolis RJ, Brasil; E-mail: edmarchiori@gmail.com Conflict of interest: There is no conflict of interest to declare. Received 05 March 2015; Received in final form 09 April 2015; Accepted 29 April 2015.
} 